\title{
Interaction between the bone morphogenetic proteins and Ras/MAP-kinase signalling pathways in lung cancer
}

\author{
KS Kraunz', HH Nelson'2, M Liu', JK Wiencke ${ }^{3}$ and KT Kelsey*,I \\ 'Department of Genetics and Complex Diseases, Harvard School of Public Health, 665 Huntington Avenue, Boston, MA 021 I5, USA; ${ }^{2}$ Department of \\ Environmental Health, Havard School of Public Health, 665 Huntington Avenue, Boston, MA 021 I5, USA; ${ }^{3}$ Department of Neurological Surgery, \\ Laboratory for Molecular Epidemiology, University of California at San Francisco, San Francisco, CA 94 I 43-044I, USA
}

Bone morphogenetic proteins (BMPs) are an integral component of the TGF $\beta$ superfamily, responsible for regulation of cell proliferation, differentiation, migration and programmed cell death in a variety of cell types. The BMPs transduce their signals directly through the SMAD family of proteins but they also have been reported to interact with the MAPK and Erk pathways. Inactivation of the BMP pathway genes has been implicated as important in several cancers. Recent work has shown that BMP3b is epigenetically inactivated in cancer and suggests that BMP6 can be epigenetically inactivated. We investigated whether BMP6 is epigenetically inactivated in cell lines and whether BMP3b and BMP6 are epigenetically inactivated in non-small-cell lung cancer (NSCLC). We also studied the relationship between BMP methylation and k-ras mutation. Here, we demonstrate that the BMP3b and BMP6 genes are common targets of epigenetic inactivation in NSCLC, and that they are significantly more likely to be concurrently inactivated $(P=0.009)$. Furthermore, this coinactivation of BMP3b and BMP6 is significantly associated with mutation of $k$-ras codon 12 in lung cancer $(P=0.003)$; those with a k-ras mutation were six times more likely to have concurrent methylation of these BMP loci. Hence, these data suggest that concurrent inactivation of the BMP and activation of the Ras signalling pathways are important in lung carcinogenesis.

British Journal of Cancer (2005) 93, 949-952. doi:10.1038/sj.bjc.6602790 www.bjcancer.com

Published online 20 September 2005

(c) 2005 Cancer Research UK

Keywords: bone morphogenetic proteins; methylation; epigenetic inactivation; k-ras mutation; non-small-cell lung cancer

$k$-ras mutation, which leads to aberrant Ras/MAP-K pro-growth signalling, has been well studied in cancer (Cunningham and Weinberg, 1985; Nelson et al, 1999; Huber and Stratakis, 2004). However, additional signalling pathways are acknowledged to play important roles in malignant disease, with the bone morphogenetic protein (BMP) signalling pathway emerging as important in multiple cancers (Nagatake et al, 1996; Tamada et al, 2001; Baldus et al, 2004; Dai et al, 2004; Kim et al, 2004). It is well recognised that the BMP signalling pathways are crucial for all stages of embryonic development, including regulation of lung development and airway branching (Weaver et al, 1999; Lu et al, 2001; Rosendahl et al, 2002). The BMPs have been shown to be growth inhibitory by suppressing proliferation (Dai et al, 2004; Haudenschild et al, 2004). They act through upregulation of the cell cycle proteins p21 and p27 (Nakamura et al, 2003; Brubaker et al, 2004; Haudenschild et al, 2004). The relationship between the TGF $\beta$ / BMP antigrowth and Ras/MAP-K progrowth signalling pathways remains unclear, but there is recent evidence of crosstalk between them (Kretzschmar et al, 1997; Yue et al, 1999; Wach et al, 2001). While BMP-2 stimulation of osteoblasts leads to activation of Ras (Nakayama et al, 2003), in Xenopus, BMP-4-stimulated erythroid differentiation is inhibited by dominant-negative activation of the Ras pathway (Xu et al, 1996). SMAD7, one of the inhibitory

*Correspondence: Professor KT Kelsey; E-mail: kelsey@hsph.harvard.edu Received 27 May 2005; revised 25 July 2005; accepted 17 August 2005; published online 20 September 2005
SMADs of the BMP/TGF $\beta$ signalling pathway, has been shown to cooperate with oncogenic Ras to escape growth arrest (Liu et al, 2003). While there is experimental evidence of an association between the BMP signalling proteins and oncogenic Ras, the nature of any interaction of BMP cytokine inactivation and $k$-ras mutation has been relatively unexplored in human tumours. As a result of the known importance of BMP signalling in the respiratory tract and the in vitro evidence of crosstalk between signalling pathways, we hypothesised that concurrent BMP inactivation and oncogenic $k$-ras mutation would be important in non-small-cell lung cancer (NSCLC).

\section{MATERIALS AND METHODS}

\section{Study population}

Eligible cases consisted of all the newly diagnosed patients with resectable lung cancer who received treatment at the Massachusetts General Hospital Thoracic Surgery Service from November 1992 to December 1996 (Nelson et al, 1999). All patients involved provided written informed consent in accordance with the appropriate institutional review boards. Patients with recurrent disease or nonoperable tumours were excluded. Tumours were snap-frozen in liquid nitrogen and stored at $-80^{\circ} \mathrm{C}$ until genomic preparation. There were 155 cases with fresh tumour DNA available to be tested for BMP3b and BMP6 methylation. Demographic and epidemiologic data, including all of the data 
on tobacco use and occupational asbestos exposure, were obtained from a self-administered questionnaire completed by patients and subsequently reviewed by a single reviewer during the hospitalisation for thoracic surgery. Asbestos exposure was defined as having any occupational asbestos exposure (yes/no), assessed as previously described (Nelson et al, 1999).

\section{Cell culture}

Lymphoblastic WTK1 and HT cells, small-cell carcinoma Shp77 cells, and non-small-cell carcinoma H322M and A549 cells were maintained in RPMI-1640 medium supplemented with $10 \%$ fetal calf serum. Prostate carcinoma DU145 cells and lung fibroblast IMR90 cells were maintained in minimum essential media (Eagle's) supplemented with $10 \%$ fetal calf serum. WTK1 cells $\left(2 \times 10^{5}\right)$ in $10 \mathrm{ml}$ media were treated with $1 \mu \mathrm{l} 5$-aza-deoxycytadine in PBS or PBS alone for 3 days and then harvested.

\section{Reverse transcription PCR}

Total RNA was isolated using Qiagen RNeasy kit. cDNA was synthesised from the RNA using the SuperScript III kit from Invitrogen. Reverse transcription PCR (RT - PCR) amplification of the BMP6 cDNA was performed using primers designed with Primer3. The BMP6 primers used are as follows: $5^{\prime}$-ACA GCA TAA CAT GGG GCT TC- $3^{\prime}$ (sense) and $5^{\prime}$-CTC GGG GTT CAT AAG GTG AA-3'. B-actin cDNA was amplified using primers supplied with the SuperScript III kit. Approximately $50 \mathrm{ng}$ of DNA was used as template. The PCR mixture contained $10 \times$ PCR buffer, dNTPs ( $200 \mu \mathrm{M}$ of each), primers ( $1 \mu \mathrm{M}$ of each) and $0.25 \mu \mathrm{l}$ TaqGold. cDNA was amplified using an annealing temperature of $60^{\circ} \mathrm{C}$ over 35 cycles. PCR product was visualised on an ethidium bromidestained agarose gel.

\section{Methylation-specific PCR}

Two sets of primers specific to the BMP6 promoter region were designed using Primer3 to amplify bisulphite-modified DNA; one specific for DNA methylated (M) at the promoter region and the other specific for unmethylated (U) DNA. The primers used are as follows: (M) 5'-GGT TTG TTG GGT AGT CGG G-3' (sense) and GCC CCT CCC CAA ATC G-3' (antisense) and (U) 5'-TTG GGT AGT TGG GTG ATT GTT-3' (sense) and $5^{\prime}$-ACA CCC CTC CCC AAA TCA- $3^{\prime}$ (antisense). Approximately $50 \mathrm{ng}$ of sodium bisuphfite-modified DNA was used as template. The PCR mixture contained $10 \times$ PCR buffer, dNTPs $(200 \mu \mathrm{M}$ of each), primers ( $1 \mu \mathrm{M}$ of each) and $0.25 \mu \mathrm{l} \mathrm{TaqGold}$. Product was amplified using an annealing temperature of $60^{\circ} \mathrm{C}$ over 38 cycles. Nontreated and SssI methylase-treated lymphocytes were used as controls. PCR products were separated by electrophoresis and visualised by ethidium bromide staining.

\section{Statistical analysis}

SAS software was used for statistical analysis. Wilcoxon rank sum test and Fisher's exact test (or $\chi^{2}$ test) were used for continuous and categorical variables in univariate analysis, respectively. Multivariate logistic regression was conducted to estimate the relationship between methylation of BMPs, k-ras mutation and covariates that were statistically significant in univariate analysis and that were important biologically.

\section{RESULTS}

\section{Methylation of BMP6 in cell lines}

In an effort to determine whether transcription of the BMP6 gene is inhibited by promoter methylation, we first examined the transcriptional status of $B M P 6$ in cell lines using RT-PCR
(Figure 1A). BMP6 mRNA was absent in WTK1 normal human lymphoblastoid cells. Following treatment with 5-aza-deoxycytadine, a DNA methyltransferase inhibitor, transcription was reactivated, demonstrating that the loss of transcription of BMP6 is due to epigenetic inactivation (Figure 1B). Using primers designed specifically to differentiate between methylated and nonmethylated DNA at the BMP6 gene promoter, we demonstrated that the WTK1 cells are methylated at the BMP6 gene promoter (Figure 1C).

\section{Methylation of BMP3b and BMP6 in NSCLC cases}

We evaluated $B M P 3 b$ and $B M P 6$ gene promoter methylation status in 155 NSCLC cases. In a consecutive case series, we found that $57 \%$ (88 out of 155$)$ and $43 \%$ (67 out of 155 ) of NSCLCs were methylated at the $B M P 3 b$ and $B M P 6$ gene promoters, respectively. Since both BMP3b and BMP6 signal in the same pathways, we tested whether there was a relationship between inactivation of the two genes. We found that $52 \%(46 / 88)$ of the cases with $B M P 3 b$ methylation were also positive for BMP6 methylation; 31\% (21/67) of cases without $B M P 3 b$ methylation were positive for $B M P 6$ methylation. This statistically significant association between concurrent methylation of $B M P 3 b$ and $B M P 6(P=0.009)$ indicates that the epigenetic silencing of these genes does not occur independently in lung cancer.
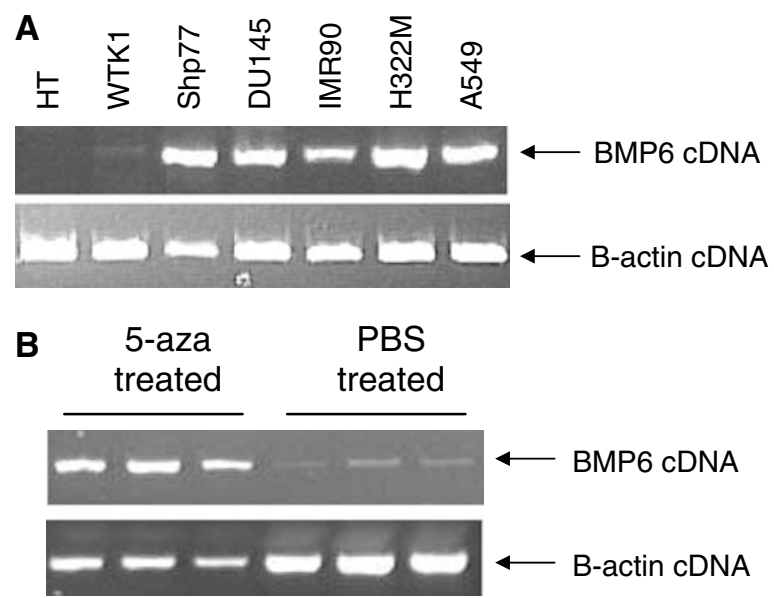

C

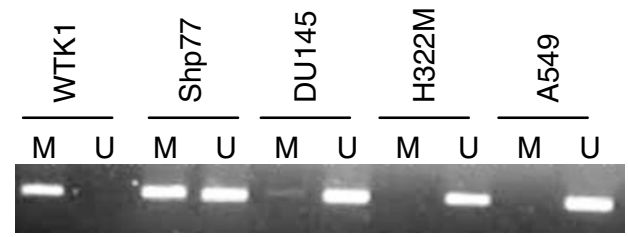

Figure I BMP6 is epigenetically inactivated in cancer cell lines. (A) BMP6 CDNA was amplified using an annealing temperature of $60^{\circ} \mathrm{C}$ over 35 cycles with the following primers: 5'-ACA GCA TAA CAT GGG GCT TC$3^{\prime}$ (sense) and 5'-CTC GGG GTT CAT AAG GTG AA-3' (antisense). The WTKI and HT cell lines did not express BMP6. (B) WTKI cells were treated with $|\mu|$ 5-aza-deoxycytadine in PBS or PBS alone for 3 days and then harvested. BMP6 is re-expressed in the WTKI cells. (C) The BMP6 gene promoter methylation status was determined by amplifying bisulphitemodified DNA using primers specific to methylated $(M)$ and unmethylated $(\mathrm{U})$ DNA. The DNA was amplified using an annealing temperature of $60^{\circ} \mathrm{C}$ over 38 cycles with the following primers: (M) 5'-GGT TTG TTG GGT AGT CGG G-3' (sense) and GCC CCT CCC CAA ATC G-3' (antisense) and $(U)$ 5'-TTG GGT AGT TGG GTG ATT GTT-3' (sense) and 5'-ACA CCC CTC CCC AAA TCA-3' (antisense). 
Table I BMP methylation and k-ras mutation in NSCLC

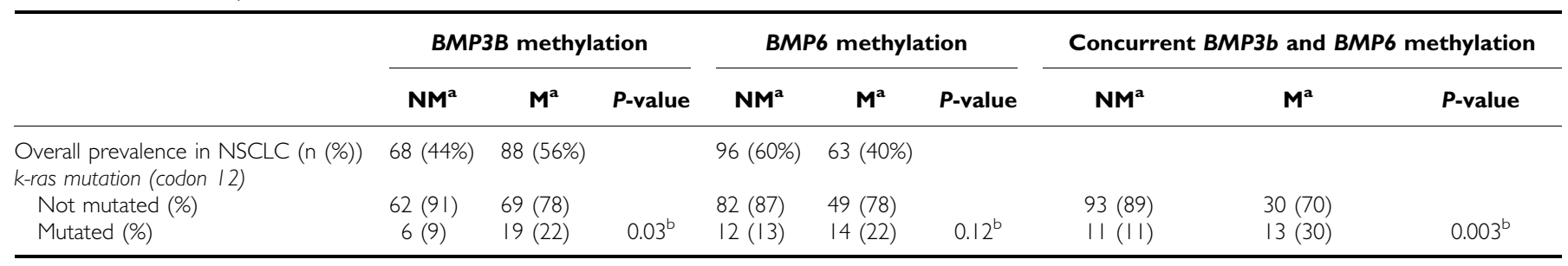

${ }^{\mathrm{a} N M}=$ not methylated; $M=$ methylated. ${ }^{\mathrm{b}} \chi^{2}$ test.

Table 2 Logistic regression modelling of BMP methylation and k-ras mutation in NSCLC

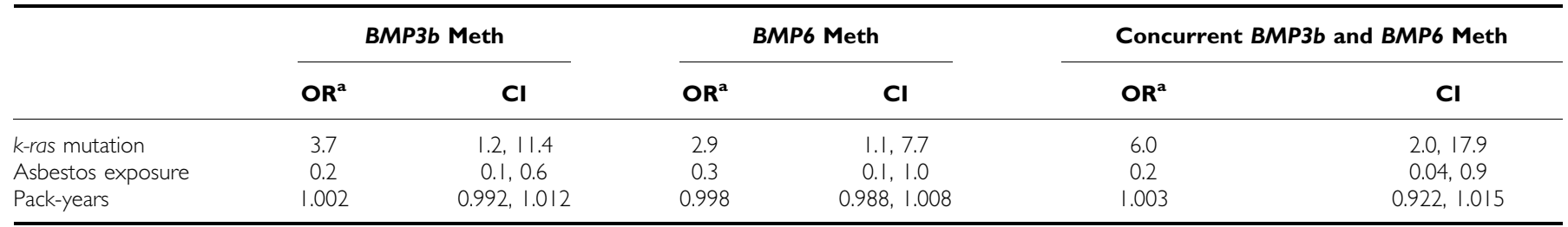

${ }^{\mathrm{a} C}$ Controlling for gender and histology.

\section{Relationship between BMP methylation and $k$-ras mutation in NSCLC}

We next investigated the relationship between BMP epigenetic inactivation and $k$-ras mutation. We previously have reported the $k$-ras mutation status of these cases (Nelson et al, 1999). In the subset of cases with both $k$-ras and BMP data, 16\% (24/147) were mutated at codon 12 of the $k$-ras gene and $B M P 3 b$ methylation was significantly associated with $k$-ras mutation (Table $1, P<0.03$ ). Those with BMP6 methylation were more likely to have $k$-ras mutation, but this was not statistically significant. However, concurrent methylation of both $B M P 3 b$ and $B M P 6$ was strongly associated with $k$-ras mutation (Table $1, P<0.003$ ).

\section{Concurrent BMP methylation, $k$-ras mutation, and tobacco and asbestos exposure in NSCLC}

$k$-ras mutation has previously been associated with asbestos exposure in these patients (Nelson et al, 1999). In addition, pulmonary interstitial fibrosis (a condition associated with asbestos exposure) is associated with activation of the BMP/SMAD signalling pathway (Matsuse et al, 1996; Rosendahl et al, 2002). Therefore, we examined the relationship between tobacco use, asbestos exposure and $k$-ras mutation, and epigenetic silencing of the BMPs (Table 2). A logistic regression analysis, controlling for histology and gender showed that tumours with $k$-ras mutation are six-fold more likely to have concurrent $B M P 3 / 6$ silencing $(\mathrm{OR}=6.0,95 \%$ confidence interval $(\mathrm{CI})=2.0-17.9)$ and asbestos exposure significantly decreased the likelihood of concurrent $B M P 3 / 6$ methylation $(\mathrm{OR}=0.2$, CI $0.1-0.9$; Table 2). There was no statistically significant relationship between BMP methylation and tobacco exposure (Table 2).

\section{DISCUSSION}

The BMPs are well recognised to play multiple crucial roles in the development of diverse tissues. They are also believed to play a role in the genesis of many tumour types, with their inactivation allowing for dysregulated cellular proliferation. There are multiple BMPs with overlapping substrate specificity (Stott et al, 1998). Our data, showing that epigenetic inactivation of $B M P 3 b$ (at a frequency similar to that previously reported (Dai et al, 2004)) and BMP6 tend to occur together in lung cancer, suggests that in NSCLC multiple BMPs may need to be silenced in order to abrogate their antigrowth signalling.

Increasing evidence shows that there is a crosstalk between TGF/BMP antigrowth signalling and Ras/MAP-K progrowth signalling, and it is likely that the interaction of these pathways is cell type and tissue specific. Some evidence suggests that Ras inactivates SMAD signalling while other evidence suggests that Ras activates SMAD signalling (Kretzschmar et al, 1997; Yue et al, 1999). Further, inhibitory SMADs have been shown to be upregulated in coordination with $k$-ras mutation in epithelial cancer (Liu et al, 2003). Although the exact relationship between BMPs and Ras in signalling are unclear, our data are consistent with the mounting evidence that the relationship is important in solid tumours.

The finding that asbestos exposure is associated with a significantly different pattern of signalling dysregulation in NSCLC supports the notion that clonal selection has important nodal points that are influenced by the pattern of carcinogen exposure. The current work suggests that the Ras and BMP pathways are part of a complex network of inter-related and interacting signalling proteins where multiple factors, including carcinogen exposure, determine the precise character of somatic genes inactivated in this particular tumour, NSCLC. In the case of BMP inactivation, there was no apparent association of methylation silencing with tobacco exposure. However, we identified an inverse relationship between asbestos exposure and BMP methylation. Asbestos exposure has been associated with cytogenetic damage in humans (Dusinska et al, 2004). Hence, asbestos may be selecting for pathway inactivation via large-scale genetic changes. For example, SMAD4, the effector protein in the BMP pathway, has been identified as mutated and deleted in lung cancer (Nagatake et al, 1996; An et al, 2002). If asbestos were associated with induction of SMAD4 inactivation in lung cancer, one would expect the inverse association with BMP silencing that we have observed.

The balance between antigrowth and progrowth signalling that is imperative for normal cell development and homeostasis is reliant upon multiple feedback signalling pathways. $k$-ras mutation has been described as a relatively early event in cancer (Nelson et al, 1999) that constitutively activates the protein leading to active growth signalling. Our data show that the BMP pathway, which is antiproliferative, is selected for inactivation preferentially 
in $k$-ras mutant tumours in NSCLC, likely as a direct means of potentiating progrowth signalling. Direct experimental investigation of this interaction in human cells and a description of the effects of different carcinogens in different tissues upon the disruption of this signalling are clearly indicated. This will more precisely define the aetiologic effects of carcinogens (such as asbestos), delineate the interlocking pathways that are dysregu- lated in solid tumours, and potentially open avenues for prevention and treatment of these often-fatal cancers.

\section{ACKNOWLEDGEMENTS}

This work was supported by CA100679, CA078609 and ES00002.

\section{REFERENCES}

An Q, Liu Y, Gao Y, Huang J, Fong X, Liu L, Zhang D, Zhang J, Cheng S (2002) Deletion of tumor suppressor genes in Chinese non-small cell lung cancer. Cancer Lett 184: 189-195

Baldus SE, Schwarz E, Lohrey C, Zapatka M, Landsberg S, Hahn SA, Schmidt D, Dienes HP, Schmiegel WH, Schwarte-Waldhoff I (2004) Smad4 deficiency in cervical carcinoma cells. Oncogene 24: 810-819

Brubaker KD, Corey E, Brown LG, Vessella RL (2004) Bone morphogenetic protein signaling in prostate cancer cell lines. J Cell Biochem 91: $151-160$

Cunningham JM, Weinberg RA (1985) Ras oncogenes in human tumours: identification, mechanism of activation and cooperative role in transformation. IARC Sci Publ 60: 359-364

Dai Z, Popkie AP, Zhu WG, Timmers CD, Raval A, Tannehill-Gregg S, Morrison CD, Auer H, Kratzke RA, Niehans G, Amatschek S, Sommergruber W, Leone GW, Rosol T, Otterson GA, Plass C (2004) Bone morphogenetic protein $3 \mathrm{~B}$ silencing in non-small-cell lung cancer. Oncogene 23: $3521-3529$

Dusinska M, Collins A, Kazimirova A, Barancokova M, Harrington V, Volkovova K, Staruchova M, Horska A, Wsolova L, Kocan A, Petrik J, Machata M, Ratcliffe B, Kyrtopoulos S (2004) Genotoxic effects of asbestos in humans. Mutat Res 553: $91-102$

Haudenschild DR, Palmer SM, Moseley TA, You Z, Reddi AH (2004) Bone morphogenetic protein (BMP)-6 signaling and BMP antagonist noggin in prostate cancer. Cancer Res 64: 8276-8284

Huber RM, Stratakis DF (2004) Molecular oncology - perspectives in lung cancer. Lung Cancer 45(Suppl 2): S209-S213

Kim IY, Lee DH, Lee DK, Ahn HJ, Kim MM, Kim SJ, Morton RA (2004) Loss of expression of bone morphogenetic protein receptor type II in human prostate cancer cells. Oncogene 23: $7651-7659$

Kretzschmar M, Doody J, Massague J (1997) Opposing BMP and EGF signalling pathways converge on the TGF-beta family mediator Smad1. Nature 389: $618-622$

Liu X, Lee J, Cooley M, Bhogte E, Hartley S, Glick A (2003) Smad7 but not Smad6 cooperates with oncogenic ras to cause malignant conversion in a mouse model for squamous cell carcinoma. Cancer Res 63: 7760-7768

Lu MM, Yang H, Zhang L, Shu W, Blair DG, Morrisey EE (2001) The bone morphogenic protein antagonist gremlin regulates proximal-distal patterning of the lung. Dev Dyn 222: $667-680$

Matsuse T, Ikegami A, Ohga E, Hosoi T, Oka T, Kida K, Fukayama M, Inoue S, Nagase T, Ouchi Y, Fukuchi Y (1996) Expression of immunoreactive activin A protein in remodeling lesions associated with interstitial pulmonary fibrosis. Am J Pathol 148: 707-713
Nagatake M, Takagi Y, Osada H, Uchida K, Mitsudomi T, Saji S, Shimokata K, Takahashi T (1996) Somatic in vivo alterations of the DPC4 gene at 18q21 in human lung cancers. Cancer Res 56: 2718-2720

Nakamura Y, Ozaki T, Koseki H, Nakagawara A, Sakiyama S (2003) Accumulation of p27 KIP1 is associated with BMP2-induced growth arrest and neuronal differentiation of human neuroblastoma-derived cell lines. Biochem Biophys Res Commun 307: 206-213

Nakayama K, Tamura Y, Suzawa M, Harada S, Fukumoto S, Kato M, Miyazono K, Rodan GA, Takeuchi Y, Fujita T (2003) Receptor tyrosine kinases inhibit bone morphogenetic protein-Smad responsive promoter activity and differentiation of murine MC3T3-E1 osteoblast-like cells. J Bone Miner Res 18: 827-835

Nelson HH, Christiani DC, Wiencke JK, Mark EJ, Wain JC, Kelsey KT (1999) k-ras mutation and occupational asbestos exposure in lung adenocarcinoma: asbestos-related cancer without asbestosis. Cancer Res 59: $4570-4573$

Rosendahl A, Pardali E, Speletas M, Ten Dijke P, Heldin CH, Sideras P (2002) Activation of bone morphogenetic protein/Smad signaling in bronchial epithelial cells during airway inflammation. Am J Respir Cell Mol Biol 27: $160-169$

Stott FJ, Bates S, James MC, McConnell BB, Starborg M, Brookes S, Palmero I, Ryan K, Hara E, Vousden KH, Peters G (1998) The alternative product from the human CDKN2A locus, p14(ARF), participates in a regulatory feedback loop with p53 and MDM2. EMBO J 17: $5001-5014$

Tamada H, Kitazawa R, Gohji K, Kitazawa S (2001) Epigenetic regulation of human bone morphogenetic protein 6 gene expression in prostate cancer. J Bone Miner Res 16: $487-496$

Wach S, Schirmacher P, Protschka M, Blessing M (2001) Overexpression of bone morphogenetic protein-6 (BMP-6) in murine epidermis suppresses skin tumor formation by induction of apoptosis and downregulation of fos/jun family members. Oncogene 20: 7761-7769

Weaver M, Yingling JM, Dunn NR, Bellusci S, Hogan BL (1999) Bmp signaling regulates proximal-distal differentiation of endoderm in mouse lung development. Development 126: 4005-4015

Xu RH, Dong Z, Maeno M, Kim J, Suzuki A, Ueno N, Sredni D, Colburn $\mathrm{NH}$, Kung HF (1996) Involvement of Ras/Raf/AP-1 in BMP-4 signaling during Xenopus embryonic development. Proc Natl Acad Sci USA 93: $834-838$

Yue J, Frey RS, Mulder KM (1999) Cross-talk between the Smad1 and Ras/ MEK signaling pathways for TGFbeta. Oncogene 18: 2033-2037 